Env. Biol. Fish. Vol. 6, No. 2, pp. 207-211, 1981

\title{
Fluctuations in the muskellunge (Esox masquinongy Mitchill) population of Chautauqua Lake, New York
}

\author{
David L. Bimber ${ }^{1,3}$ \& Stuart A. Nicholson ${ }^{2,4}$ \\ ${ }^{1}$ Environmental Resources Center \& the Department of Biology, State University College, Fre- \\ donia, New York 14063, U.S.A. \\ ${ }^{2}$ School of Natural Resources, The University of the South Pacific, Suva, Fiji
}

Keywords:

Fish, Ecology, Population density, Exploitation, Tagging, Catch per effort

\section{Synopsis}

Population and exploitation estimates were made from angler recaptures of Chautauqua Lake muskellunge, Esox masquinongy Mitchill. Fish were tagged during Conservation Department studies in 1941-1946, 1961-1965 and 1976-1978. Population estimates of adult fish ranged from one to seven fish per hectare and angler exploitation rates of tagged fish fluctuated from $3.8 \%$ to $14.1 \%$. Relative catch indicators suggest a major decline in the lake's muskellunge population during the last decade. Overexploitation, habitat alteration and interspecific competition with recently introduced fish species were cited as probable causes of the decline.

\section{Introduction}

The sport fishery for muskellunge, Esox masquinongy Mitchill, in Chautauqua Lake, New York enjoys high yields and trophy catches. In 1975 muskellunge anglers contributed over 3.2 million dollars to the watershed's economy (Horn 1978). The New York State Fish Commission pioneered hatchery propagation of muskellunge in 1888 . During the early part of this century the muskellunge fishery was highly productive and even supported a limited commercial fishery that peaked during the Depression era (Evermann \& Goldsborough 1901, Moore 1936, Heacox 1946). Heacox (1946) suggested that overexploitation and interspecific competition were causes of a severe decline in muskellunge catch during the late 1930's. The State Conservation Department implemented new angling and harvest restrictions in 1941.

\footnotetext{
3 Present address: Great Lakes Research Division, Institute of Science and Technology, University of Michigan, 2200 Bonisteel Blvd., Ann Arbor, Michigan 48109, U.S.A.

4 Present address: St. Lawrence-Lastern Ontario Commission, Watertown, New York, 13601, U.S. A.
}

Received 7.9.1979 Accepted 12.5.1980
These regulations were believed responsible for subsequent improvements in catch (Mooradian \& Shepherd 1973).

The New York State Department of Environmental Conservation (DEC) has monitored the population since 1941. Although their data are extensive, few analyses have been published. Recent declines in angling and broodstock catches have prompted speculation on the status of the fishery. In this paper we review relative indices of population levels over the past several decades and absolute estimates of density and exploitation gauged from major DEC surveys in 1941-1946, 1961-1965 and 1976-1978.

\section{Methods}

Chautauqua Lake is located in southwestern New York State within the upper reaches of the Ohio River drainage. This shallow eutrophic lake has a normal elevation of $399 \mathrm{~m}$, is $27.9 \mathrm{~km}$ long and from 1.6 to $3.5 \mathrm{~km}$ wide, with a mean depth of $5.7 \mathrm{~m}$ and area of 5324 ha (Mayer et al. 1978). Littoral zone rooted aquatic macrophytes provide cover and abun- 
dant forage for over 50 fish species in the lake (Bimber 1978).

We evaluated DEC data from sales of special muskellunge licenses and spring broodstock trapnetting. DEC has required a special muskellunge license since 1941. Anglers are asked to return licenses at the end of the fishing season with a report of the number of muskellunge caught, length, tag numbers (if present) and an estimate of angling effort. Since 1960, license returns have averaged $23 \%$ of total annual license sales. Mooradian \& Shepherd (1973) examined angler catch and effort trends over one decade. Further discussion of these data are omitted from our analyses.

The DEC nets broodstock muskellunge every spring. Spring nets have been positioned at various locations around the lake since operations began in the late 1880 's. Currently five or six nets are fished during the spawning season, but as many as nineteen have been used in previous years. Hatchery personnel record data on age, sex and length besides taking gametes for propagation. From 1941 to 1946 and 1961 to 1965 approximately 7800 and 5900 muskellunge were tagged with Monel strap-type tags attached to the anterior part of the dorsal fin. This tag probably has minimal effect on growth and survival of adult muskellunge (Bimber 1978, NYSDFC, Region 9, Olean, N.Y, unpublished data).

To reduce bias caused by annual variations in fishing intensity, an estimate of fishing effort was incorporated into raw data accumulated during broodstock netting and from return of angler licenses. Angler catch-per-effort (CPE) was estimated from actual catch reported by anglers divided by the number of muskellunge licenses returned in that year. Broodstock catch was also standardized to best evaluate trapping effort. Several (5) nets were selected as the most uniform indicators of the relative abundance of the spring spawning muskellunge stock. Since 1941, these five index nets were fished for equivalent time periods at approximately the same locations in the lake (Bimber 1978). Angler tag returns provided recapture data for up to 20 years following each tagging period. These data were used to estimate stock size and exploitation rates of tagged fish. Muskellunge of all sizes were tagged but only those of legal length when tagged $\geqslant 81.3$ $\mathrm{cm}$ in 1941-1946, $\geqslant 76.2 \mathrm{~cm}$ in $1961-1965$ and 1976-1978) were used in analyses of exploitation and stock size. Tags used during the years 1941-1946 and 1961 were simply identified as property of DEC and posters were placed around the lake to alert anglers to presence of tags. In subsequent studies the tags were additionally marked with a DEC address. In some recent years local fishing contests have also encouraged return of tags.

Stock estimates $(\mathrm{N})$ and their standard errors $(\mathrm{SE}(\mathrm{N}))$ were made from first-year angler recaptures of fish tagged the previous spring using the formulas:

$\mathrm{N}=\frac{\mathrm{M} \cdot \mathrm{C}}{\mathrm{R}}, \quad \mathrm{SE}(\mathrm{N})=\mathrm{N} \quad \sqrt{\frac{(\mathrm{N}-\mathrm{M}) \cdot(\mathrm{N}-\mathrm{C})}{(\mathrm{M} C) \cdot(\mathrm{N}-1)}}$,

where $M$ is the number of fish marked, $C$ is the total number examined for marks and $R$ is the number of marked fish recaptured by anglers. Exploitation rates (u) for the first year that tags were extant were calculated using: $u=R / M$ (Ricker 1975).

\section{Results and discussion}

Both broodstock and reported angler catch suggest that the Chautauqua Lake muskellunge population has fluctuated greatly over the period of record (Fig. 1). Peaks in angler catch in 1952, 1962 and 1969 were followed by major declines. These variations are consequences of differential fishing pressure. A strong positive correlation existed between fluctuations in license sales and reported catch (Pearson $r=+0.76$, $P<0.01)$. In recent years an extreme decline is evident in both variables. The 1974 reported catch (419) was the lowest recorded.

Broodstock catch has also oscillated with major catch peaks occuring in $1910,1919,1924,1946-48$, 1954, 1961 and 1964-70 (Fig. 1). A long-term decline was evident after 1910 leading to 'collapse' of the broodstock in the late 1930's and subsequent implementation of increased angling restrictions (Mooradian \& Shepherd 1973). Angler catch soon in-

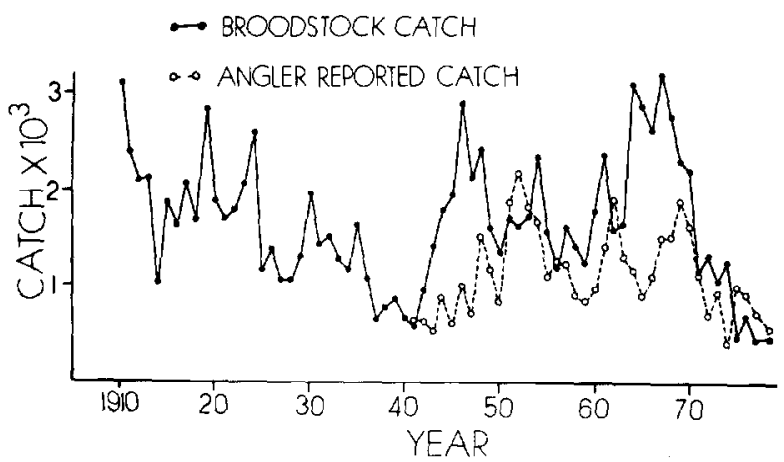

Fig. 1. Total annual broodstock and angler reported catch of muskellunge from Chautauqua Lake, 1910-1978. 
creased and remained at high levels in subsequent decades. However, broodstock catch has varied markedly and in recent years has substantially declined. Recent catches have dipped below those of the period of collapse (1935-1940) and the 1975, 1977 and 1979 broodstock catches have been the lowest on record. Although broodstock catch is additionally dependent upon factors other than population density (e.g., weather, water conditions, spawning habitat etc.), it is unlikely that these could account for the consistent recent decline noted in Figure 1.

Angler catch per license year (angler CPE) also suggest that catchable muskellunge stock levels have varied irregularly since 1941 , but show no clear indication of major recent decline (Fig. 2). Angler CPE has averaged 0.4 fish per license during the last decade. During the same period DEC estimates of total catch averaged 4860 muskellunge per year (DEC unpublished data Region 9, Olean, NY). When broodstock catch is adjusted for effort, considerable oscillation is evident with catch peaks occurring in 1946, $1954,1960,1964$ and 1967. Several peaks in broodstock CPE were followed by corresponding increases in angler CPE 2-3 years later, a probable result of recruitment of the previously sublegal portion of the broodstock to the fishery.

The use of angler and broodstock CPE may be of limited accuracy as measures of relative population size. The consistency of angler return information is complicated by its direct relationship with license sales and catch regulations rather than population density. Although absence of major trends in angler CPE would appear to indicate no appreciable reduction in the population, apparent stability may be the result of reduced angler demand (license sales) at a time of reduced availability of muskellunge. Since license

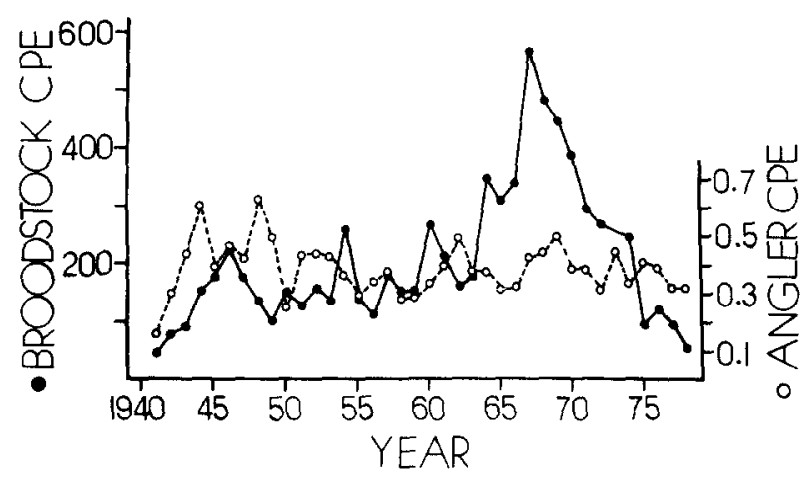

Fig. 2. Broodstock and angler CPE for the Chautauqua Lake muskellunge fishery, 1941-1978.
Table 1. Muskellunge stock and exploitation estimates from DEC tagging data.

\begin{tabular}{|c|c|c|c|c|}
\hline \multirow{2}{*}{$\begin{array}{l}\text { Year of } \\
\text { tagging }\end{array}$} & \multirow{2}{*}{$\begin{array}{l}\text { Exploitation } \\
\text { rate }(u)\end{array}$} & \multicolumn{3}{|c|}{ Stock estimate } \\
\hline & & Mean & \pm & $\mathrm{SE}$ \\
\hline 1978 & 0.1033 & 5.312 & & 836 \\
\hline 1977 & 0.1204 & 5.990 & & 1.182 \\
\hline 1976 & 0.1414 & 6.642 & & 940 \\
\hline 1965 & 0.0577 & 15.687 & & 3.384 \\
\hline 1964 & 0.0682 & 17.369 & & 2.792 \\
\hline 1963 & 0.0812 & 16.426 & & 2.795 \\
\hline 1962 & 0.0623 & 30.679 & & 5.208 \\
\hline 1961 & 0.0382 & 37.518 & & 9.451 \\
\hline 1945 & 0.0556 & 11.052 & & 2.739 \\
\hline 1944 & 0.0658 & 13.315 & & 3.294 \\
\hline 1943 & 0.0523 & 10.461 & & 3.352 \\
\hline 1942 & 0.0422 & 15.565 & & 1.352 \\
\hline 1941 & 0.0544 & 11.390 & & 2.825 \\
\hline
\end{tabular}

sales have declined, stable CPE could also be caused by the remaining experienced anglers continuing to catch fish after novice anglers had dropped out of the fishery. Currently (1974-1978), license sales are reduced $31 \%$ from those of the 1960's. During the same period, angler CPE has only declined $11 \%$, thus implying an increase in exploitation intensity. Broodstock CPE is a less biased estimator of population density. It relies upon the assumption that there have been no major shifts in muskellunge distribution throughout the lake over the years. In some instances broodstock CPE is predictive of trends in angler CPE and, as such, indicates no significant improvement in angler catch for the next few years.

Stock estimates based on the results of tagging studies (Table 1) include only legal length muskellunge because only angler harvest data were used in their computation. Tag loss during the period between spring tagging and the close of the muskellunge season was assumed to be minimal. Stock estimates for the first study (1941-1945) appeared relatively stable ranging from 1.96 to 2.92 fish per ha $(\mathrm{x}=2.32)$. Stock densities for the second period (1961 1965) were almost double those of the first $(\bar{x}=4.42$, range 2.95 to 7.05 fish per ha). Most recent estimates (1976-1978; $\bar{x}=1.13$ fish per ha) correspond with the decline suggested by relative indicators of stock density. The 1978 estimate, approximately one legal muskellunge per ha is the lowest on record. It should be noted that these estimates refer only to the number of legal (76.2 $\mathrm{cm}$ in length or larger) size individuals in the population during late April or early May of the tagging year. Morc recent analyses indicate that by the fall of the year, recruitment via growth 
may account for an addition of 20 to $40 \%$ to the catchable muskellunge stock (Bimber, unpublished data).

First-year exploitation of tagged muskellunge fluctuated from $3.8 \%$ to $8.1 \%$ for the first two tagging studies (Table 1). Averages for the periods 1941-1945 and $1961-1965$ were $5.4 \%$ and $6.2 \%$, respectively. The 1976-1978 exploitation estimates $(\bar{x}=12.2 \%)$ were much greater. If the present muskellunge population has diminished, the percentage of tagged fish may represent a relatively larger proportion of the population. Thus exploitation of tagged fish may have increased while catch appeared to remain stable. These estimates represent minimum exploitation of tagged fish due to tag loss, the incomplete reporting of tags and a limited sample size. Recent work indicates that the upper ranges of exploitation may approach four times these minima (Bimber, unpublished data).

Data reviewed strongly suggest that the Chautauqua Lake muskellunge population has fluctuated considerably in the past, but has declined most sharply in the last decade. Causes of this decline are poorly understood. Exploitation may be further reducing the population during the current period of low density. Data indicate that under present regulations, many females are subject to removal after unly one or two reproductive seasons, a problem that may be exacerbated by recently noted increases in length and weight at age (Bimber 1978). During the period 1941-1969, an average of $30 \%$ of the spawning female stock was protected by regulation, but since 1970 this has decreased to $11 \%$.

Long-term changes in the aquatic flora of the lake and more recent disruptions in these macrophyte communities by herbicide treatments (sodium arsenate, 2,4-D and Diquat) and mechanical harvesting may have had significant influence on the viability of the lake's fish community and may well have adversely affected localized muskellunge stocks. Esocids are highly specific in site selcction for spawning and rely heavily on aquatic vegetation for concealment during early ontogeny and as a source of forage fishes (Franklin \& Smith 1963, Frost \& Kipling 1967, McCarraher \& Thomas 1972). In addition to temporarily destroying cover over large areas, these treatments may cause fundamental changes in species composition of localized macrophyte communities. Initial avoidance reactions to these chemicals may increase vulnerability of young muskellunge and contribute to increased competition and energy expenditures (stress) for both young and adult fish as a result of movements, crowding, increased predation etc. Treatment also has a negative impact on invertebrate (Nicholson \& Clerman 1973) and forage fish stocks (Bimber et al. 1976, May et al. 1973, Wilson \& Bond 1969) via direct or sublethal toxicity and food chain contamination. Density of muskellunge stocks may also be declining because of competition with or predation by a number of recently introduced species, especially walleye (Stizostedion vitreum vitreum). The appearance of the first strong walleye year classes coincides roughly with the beginning of the decline in muskellunge recruitment in the mid to late 1960's.

In summary, data reviewed strongly suggest that the muskellunge population of Chautauqua Lake is declining. The most probable causes for this recent decline include overexploitation, degradation of muskellunge habitat and food supply by herbicides or harvesting, interactions with recently introduced fishes, particularly walleye and basic instability of population control mechanisms (e.g. natality, mortality, recruitment etc.). A more detailed examination of current information, especially recruitment is highly desirable and consideration of additional catch restrictions may be needed to prevent continued stock depletion. Additionally, effects of recent shifts in the predator composition of the lake's fish community should be a focus of future research.

\section{Acknowledgements}

We gratefully acknowledge the cooperation of the New York State Department of Environmental Conservation which provided access to most of the data reviewed. We especially thank the staffs of the Chautauqua Muskellunge Hatchery, Mayville, NY and the NYSDEC Region 9 office, Olean, NY. We also appreciate criticisms of earlier drafts by J. D. Winter, R.W. Boenig, J. Parker, D. Toews, W. Hadley, S. Mooradian, A. Nigro, D. W. Einhouse, D. Jude and L. Fuiman.

\section{References cited}

Bimber, D. L., R. W. Buenig \& M. L. Sharma. 1976. Respiratory stress in yellow perch induced by subtoxic concentrations of Diquat. Ohio J. Sci. 76: 87-90.

Bimber, D. L. 1978. An analysis and historical overview of the muskellunge population and sport fishery of Chautauqua Lake, New York. M. S. thesis, State University College, Fredonia, N.Y. 150 pp.

Evermann, B. L. \& E. L. Goldsborough. 1901. Notes on the fishes and mollusks of Lake Chautauqua, New York. U.S. Comm. Fish Fish. Rep. 1901: 169-175. 
Franklin, D. R. \& L. L. Smith, Jr. 1963. Early life history of the northern pike, Esox lucius L., with special reference to the factors influencing the numerical strength of year classes. Trans. Amer. Fish. Soc. 92: 91-110.

Frost, W. E. \& C. Kipling. 1967. A study of reproduction, early life, weight-length relationship and growth of pike, Esox lucius L., in Windermere. J. Anim. Ecol. 36: 651-693.

Heacox, C. E. 1946. The Chautauqua Lake muskellunge: research and management applied to a sport fishery. Trans. 11 th N. Amer. Wildl. Conf. 11: 419-425.

Horn, T. 1978. Significance of the Chautauqua Lake (New York) muskellunge fishery to regional tourism in 1975. Cornell Univ. Nat. Resour. Res. and Ext. Serv. Series No. 11. $121 \mathrm{pp}$.

May, B. E., R. S. Hestand \& J. M. van Dyke. 1973. Comparative effects of Diquat plus copper sulfate on aquatic organisms. Weed Sci. 21: 241-253.

Mayer, J. R., W. M. Barnard, W. J. Metzger, T. A. Storch, T. A. Erlandson, J. R. Luensman, S. A. Nicholson \& R. T. Smith. 1978. Chautauqua Lake - watershed and lake basin. pp. 1-103. In: J. Bloomfield (ed.) New York State Monograph Series, N.Y. State Department of Environmental Conservation.

McCarraher, D. B. \& R. E. Thomas. 1972. Ecological significance of vegetation to northern pike, Esox lucius, spawning. Trans. Amer. Fish. Soc. 101: 560-563.

Mooradian, S. R. \& W. F. Shepherd. 1973. Management of muskellunge in Chautauqua Lake. N.Y. Fish Game J. 20: $152-157$.

Moore, E. 1936. A creel census at Chautauqua Lake, New York. Trans. Amer. Fish. Soc. 67: 130-138.

Nicholson, S. A. \& R. J. Clerman. 1973. Toxicity of Diqual to the crustacean amphipod Hyallella from Chautauqua Lake. Environ. Lett. 7: 215-227.

Ricker, W. E. 1975. Computation and interpretation of biological statistics of fish populations. Fish. Res. Board Can. Bull. $191.382 \mathrm{pp}$.

Wilson, D. C. \& C. E. Bond. 1969. The effects of the herbicides Diquat and Dichlobenil (Casoron) on pond invertebrates. Part I. Acute toxicity. Trans. Amer. Fish. Soc. 98: $438-443$. 